\title{
The Backseat Passenger Protection Point of View in Car Design Requirements
}

\author{
J. Kadlecová* \& J. Kovanda \\ Faculty of Transportation Sciences, Czech Technical University in Prague, Czech republic \\ *Corresponding author: kadlecova@fd.cvut.cz
}

\begin{abstract}
Backseat passenger protection, either for the protection of children or adults, is more limited than on the front seats. It is caused by the smaller possibility to secure the passenger in the appropriate seating position and, in the case of children, reduce control of their behaviour during the journey by the driver. Any misuse causes serious injuries and fatalities, which, moreover, have a significant impact on national economies and society (serious injuries, loss of workforce, life-long treatment, etc.), and which should be decreased. Even though there is no regulation dedicated to this area, the producer should take it into account in the designing stage - in cooperation with suppliers of the respective parts. Quality Function Deployment and Voice of Customer, where society is the customer of the car producer can be implemented.
\end{abstract}

KEY WORDS: Passive safety, child restraint system, passenger protection, QFD, VoC.

\section{INTRODUCTION}

Based on the statistics and results of local researchers, there is a high percentage of rear seatbelt misuse. Especially with children, permanent control is necessary. It was proved through various research led in Europe and in the USA that in the majority of all uses of CRS there was some kind of misuse found - either lack of CRS harness adjustment, improper fixation of the CRS in the car or the child was not properly fastened. In the case of a collision with an unfastened child there is the risk of firing the child out of the car or serious injuries caused by the possibility to move around the interior of the car. Of course we can find some misuse with adult passengers, but in case of adults, the case doesn't involve so many different failure sources.

\section{EXPERIMENTS}

Department of Transportation Technology has performed various crash test experiments. Some of these experiments involved a backseat passenger - a P3 dummy in CRS. There were, among others, a frontal collision of small vehicle and rigid barrier, vehicle-vehicle collision, and side collision of car and motorbike where the dummy was situated on the crash side. The conditions with the experiments were set in accordance with the EU regulations for vehicle testing - ECE R 12, ECE R 94, ECE R 95 as the key 
regulations. The CRS in experiments was approved in accordance to ECE $R 44$ for the appropriate mass category. As the dummies were equipped with the three-axis sensors for acceleration measurement, the resulting experimental data can be considered to be reliable. For further evaluation, the performance of the child dummy is significant. In both cases, the Head Performance Criteria of the child dummies in restraint systems is low enough to assure a moderate injury in worst cases: Situation: Frontal collision Renault 5 vs. rigid barrier, $40 \%$ overlap in the collision, child dummy situated on the left-rear seat. Collision speed: $50 \mathrm{kph}$.

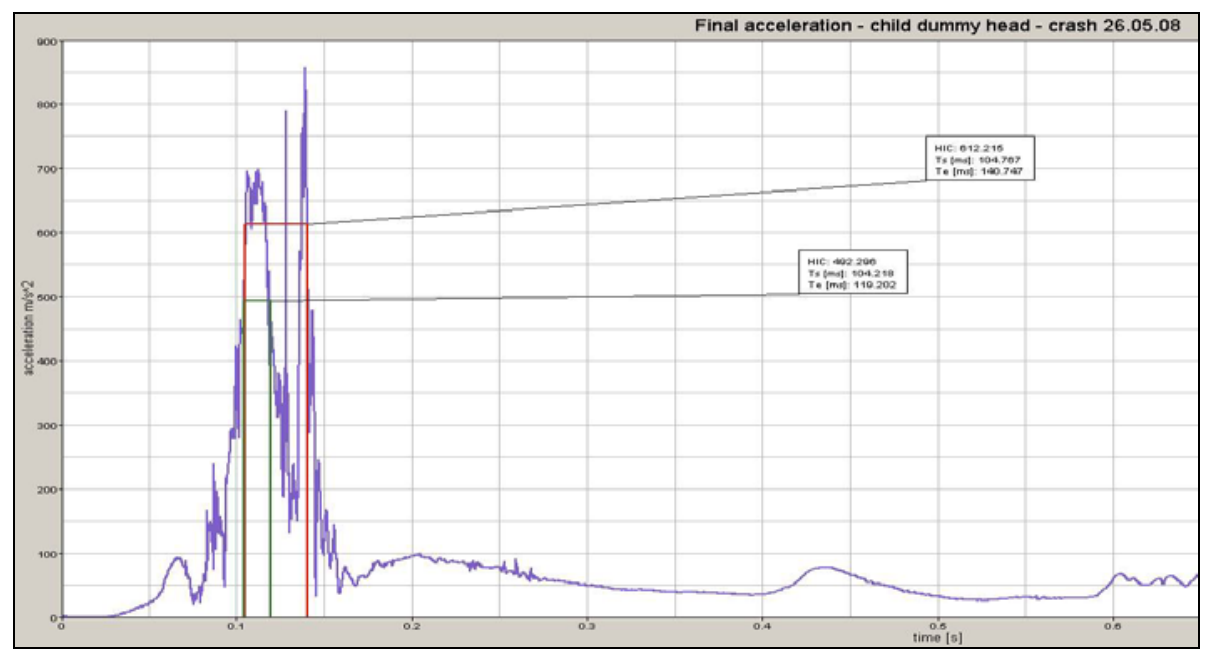

Figure 1: Performance criteria Vehicle-Rigid Barrier

Head Performance Criteria: $\mathrm{HPC}_{15}=492$; $\mathrm{HPC}_{36}=612$. Expected injury: The child will probably suffer minor to moderate head injuries resulting from the head contact with backrest and front seat (was not apparent due to outer parts of the car body, but is expected from the measured data). As there was no performance measured in the abdominal and thorax area, we cannot presume other injuries. In the second recently performed experiment, a car with a child passenger was crashed into by a motorbike. The child dummy was positioned on the collision-side of the vehicle and the CRS was again conforming to the ECE R 44 requirements. Situation: Skoda Octavia Estate collided by a motorbike at the area of back door (dummy positioned at the door). Collision speed $59 \mathrm{kph}$ (motorbike), the car is static.

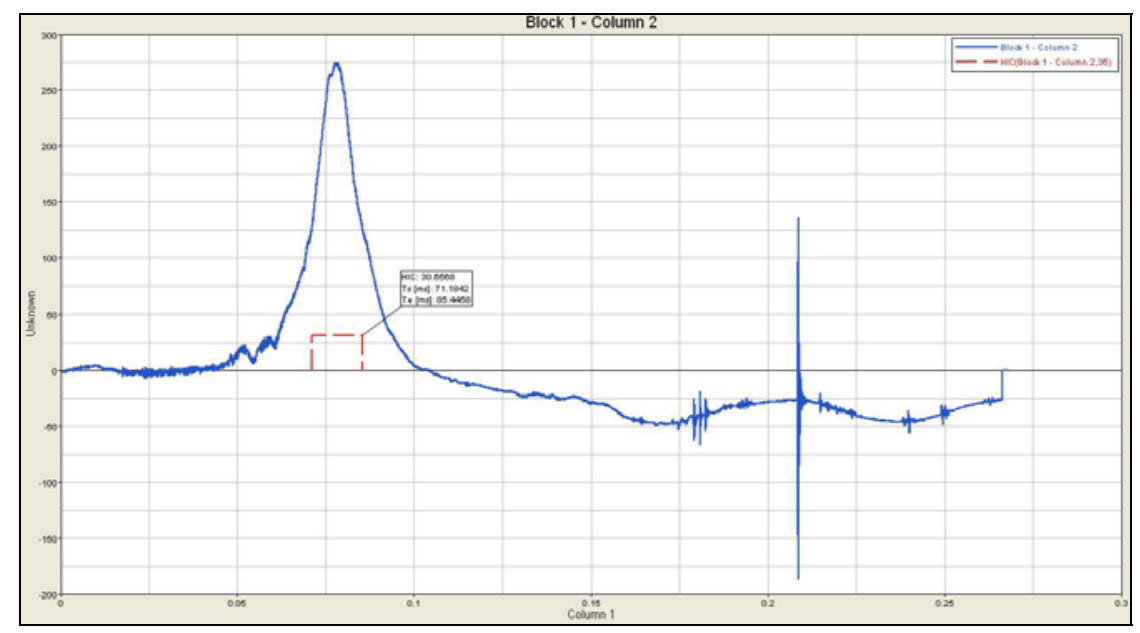

Figure 2: Performance criteria Vehicle-Motorbike 
Head Performance Criteria: $\mathrm{HPC}_{15}=31$. In this case, the child should not suffer from any long-lasting pain cause by head injury (thorax and abdominal area are not measured; therefore no assumption can be made). To be able to evaluate the overall likelihood of serious injuries with children on the back seats, it is necessary to measure other performance criteria. Based on Head Performance Criteria, we can expect the children should not attain injuries leading to long-time unconsciousness and resulting brain damage. In the above mentioned experiments, the dummies were well protected as there was no misuse in the CRS use. Based on the statistics of child injuries in crashes, there is a very significant difference between the level of children injured/fatally injured in crashes in the EU countries and in the USA (the level can slightly differ because of the national statistics). As there is no relevant detailed information about the accident conditions, we can only presume that, ceteris paribus, in the USA, more spacious cars are more often used, and therefore the passengers in CRS (those are the passengers under 14) are less likely to get in touch with the interior of the vehicle and are more prevented from contact with the interior, e. g. the front seat. Especially in side-collisions, it is very important for older children using booster seats, that prove lower protection levels against side impact and the internal seatbelts of the car are used.

\section{IMPLEMENTATION}

The implementation of the experiment and statistics results is therefore done according to this scheme:

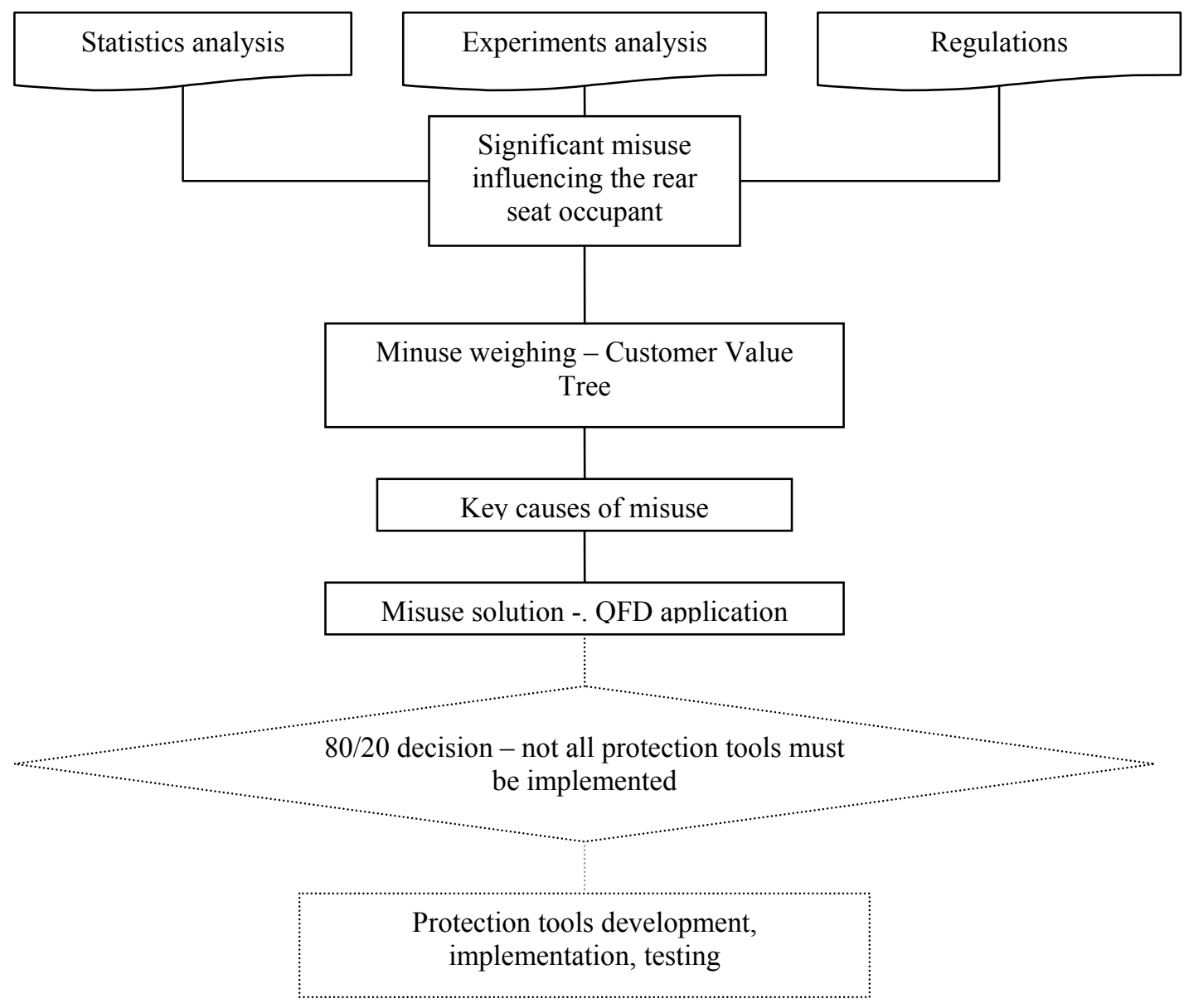

Figure 3: Workout procedure 
The data that can be obtained from modelling the possible frontal collision situations show the restraints are the most important point in life protection on back seats (Hoščuk, 2001). The information is taken into account for Customer Value Tree design (seatbelt vs. signalisation importance):

Table 1: Performance criteria

\begin{tabular}{|c|c|c|c|c|c|}
\hline & Unrestrained & Restrained & Airbag & Restrained, airbag & Critical value \\
\hline GSI & $\mathbf{1 2 6 2 4 , 0}$ & 208,0 & $\mathbf{4 0 2 6 , 9}$ & 193,3 & 1000 \\
\hline HIC & $\mathbf{4 5 5 0 , 2}$ & 93,7 & $\mathbf{3 2 3 6 , 9}$ & 107,8 & 1000 \\
\hline
\end{tabular}

Based on the Customer Value Tree results and Quality Function Deployment results it is clearly apparent that the seatbelt control is the key issue to improving the CRS misuse values and the quality of rear passenger protection.

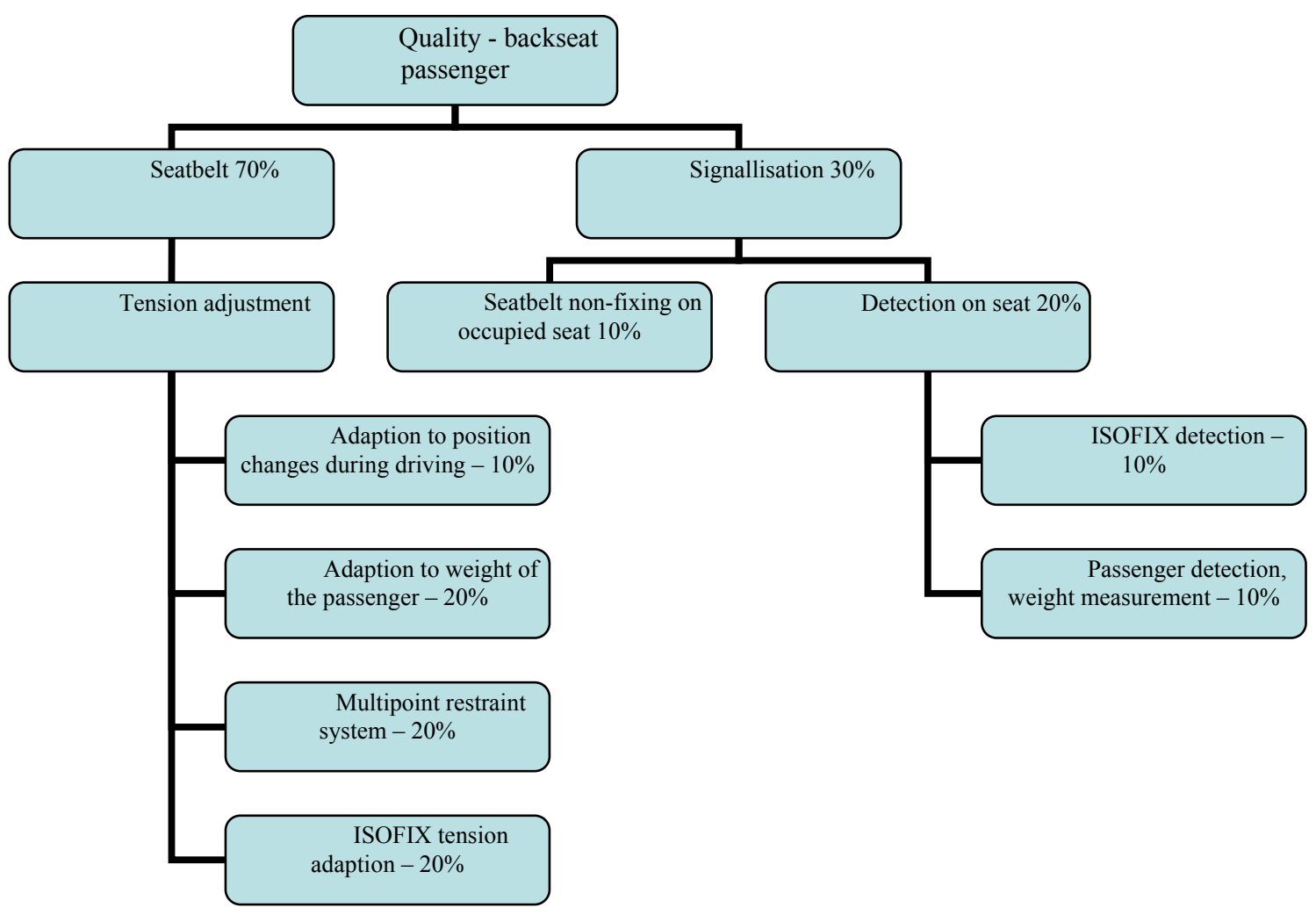

Figure 4: Customer Tree Analysis

The percentages of the above mentioned chart are partly taken from modelling (for lower levels), and partly from injury statistics (the division of restrained/unrestrained cases and the impact on passenger). More about the topic can be found in (Kadlecova, 2009).

In case the rear seatbelt functionality can be adjusted according to the passenger on the seat, it may be possible to reduce the misuse of seatbelt by the older children travelling in booster seats. It can happen intentionally - when the seatbelt pretension is universally set, when the CRS is improperly positioned or the CRS is fixed by the seatbelt only; or unintentionally - the sleeping child is leaning out of the CRS (booster seat without harness) when, for example, they have fallen asleep on a longer journey. In case this situation happens, 
with standard equipment, the child travels in the following position, without any possibility of the driver to improve the outcome.

It is very understandable that the older children have bigger freedom to re-set the transport conditions to a completely different setting, due to the lack of possibility to fix the situation or just due to their free will.

The values from the above mentioned Picture 4 were used to make up a part of the QFD chart, and, as shown in the field Relative weight, the seatbelt adjustment is a key point in possible improvement of passengers:

\begin{tabular}{|c|c|c|c|c|c|c|c|c|c|c|c|}
\hline \\
\hline \multicolumn{12}{|c|}{$\begin{array}{l}\text { Relationship Between Requirements: } \\
9 \text {-Strong } 3 \text { - Moderate } 1 \text { - Weak }\end{array}$} \\
\hline & & & Column Number & 1 & 2 & 3 & 4 & 5 & 6 & 7 & 8 \\
\hline & & & Max Relationship Value in Column & 9 & 9 & 9 & 9 & 9 & 9 & 9 & 9 \\
\hline & & & Requirement Weight & 640 & 580 & 220 & 420 & 460 & 540 & 360 & 280 \\
\hline & & & Relative Weight & 18,29 & 16,57 & 6,29 & 12,00 & 13,14 & 15,43 & 10,29 & 8,00 \\
\hline & & & $\begin{array}{r}\text { Difficulty } \\
(0=\text { Easy to Accomplish, } 10=\text { Extremely Difficult }) \\
\end{array}$ & 2 & 3 & 1 & 5 & 3 & 7 & 3 & 4 \\
\hline & & & Minimize ( $\mathbf{v})$, Maximize $(\mathbf{\Delta})$, or Target $(\mathbf{x})$ & $\Delta$ & $\Delta$ & $\Delta$ & $\Delta$ & $\Delta$ & $\Delta$ & $\Delta$ & $\Delta$ \\
\hline 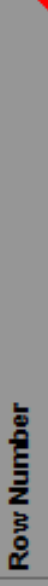 & 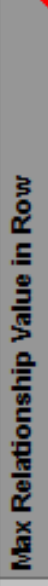 & 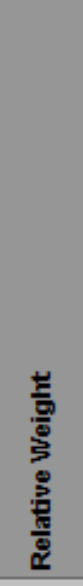 & $\begin{array}{r}\text { Quality } \\
\text { Characteristics } \\
\text { (a.k.a. "Functional } \\
\text { Requirements" or } \\
\text { "Hows") }\end{array}$ & 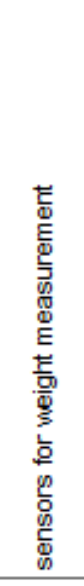 & 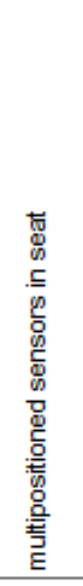 & 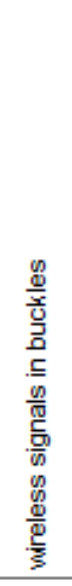 & 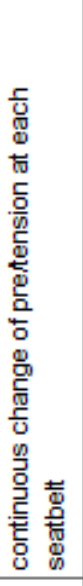 & 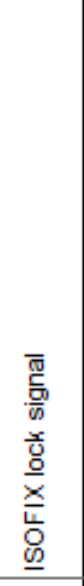 & 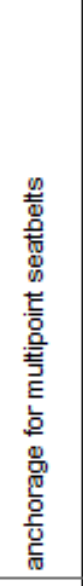 & 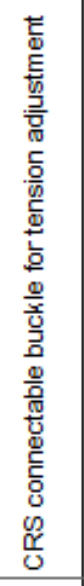 & 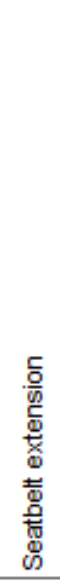 \\
\hline 1 & 9 & 10,00 & seat belt fastening signallisation & 1 & 1 & 9 & 3 & 9 & 1 & 1 & 1 \\
\hline 2 & 9 & 10,00 & seat occupation detection & 9 & 9 & 3 & 3 & 1 & 1 & 1 & 3 \\
\hline 3 & 9 & 10,00 & ISOFIX detection & 3 & 1 & 3 & 3 & 9 & 1 & 3 & 1 \\
\hline 4 & 9 & 20,00 & ISOFIX seatbelt tension adjustment & 9 & 1 & 1 & 3 & 9 & 9 & 9 & 3 \\
\hline 5 & 9 & 10,00 & asynchronous tensioning & 9 & 9 & 1 & 3 & 1 & 9 & 1 & 9 \\
\hline 6 & 9 & 20,00 & multipoint seatbelts on back seats & 3 & 9 & 1 & 9 & 1 & 9 & 3 & 1 \\
\hline 7 & 9 & 20,00 & adaption to weight of the passenger & 9 & 9 & 1 & 3 & 3 & 3 & 3 & 3 \\
\hline
\end{tabular}

Figure 5: QFD Chart

The chart represents the results of the evaluation for the backseat restrain system parts and installation. It is necessary to mention the values in QFD charts are always the result of subsequent analyses of different professionals with a deep knowledge of their field of work 
- in this case, at least knowledge of car body design, vehicle dynamics and electrical engineering is significant.

There are new tasks to solve before the elements are incorporated and final price is set. Therefore it is now the task of the producer to arrange the conditions on the back seat to improve possible manageability by the driver and lower the possibility of misuse by the backseat occupant. To do so, technical changes should be implemented and tests undertaken. As shown in Picture 1, this procedure is not a part of quality tools application at this stage.

\section{ACKNOWLEDGMENT}

Here with the authors would like to express the grateful thanks to Prof. Zdeněk Votruba for the inspiring ideas related to the subject of this article.

\section{REFERENCES}

HOŠČUK: Bezpečnost cestujicích na zadnich sedadlech (Safety of Backseat passengers), Diploma Thesis, CTUP, 2001, Prague.

KADLECOVÁ: Quality Management Methods in New Product Development, CTUP, 2009, Prague.

KOVANDA: Kolize osobni automobil - pevná bariera (the Car-Rigid Barrier Collision). Výzkumná zpráva, VYZ 616.005/08, ČVUT v Praze, Praha. 2008. 